\title{
Adaptation of High-Variant Automotive Production System Using a Collaborative Approach
}

\author{
Jonatan Berglund, Liang Gong, Hanna Sundström \\ and Björn Johansson
}

\begin{abstract}
Automotive manufacturing systems are high investment assets in need of continuous upgrades and changes to remain relevant and effective. The complexity of such a system is reflected in the difficulty of making holistically informed decisions regarding the upgrades and changes. To reach holistic and sound decisions it is important to collaborate between departments, experts, and operational actors during the planning and development of upgrades and changes. Such collaboration should be supported by tools, models, and methods that facilitate understanding and enable the users to express their input and feedback in a clear and understandable manner. This chapter describes the development and evaluation of one set of tools. The developed tools combine 3D imaging and virtual reality technologies to facilitate the creation of decision support models that are accurate, realistic, and intuitive to understand. The developed tools are evaluated by industrial engineers in the area of manufacturing $R \& D$.
\end{abstract}

Keywords 3D-imaging - Collaboration - Cross-functional teams • Manufacturing $\cdot$ Virtual reality $\cdot$ Simulation and modelling $\cdot$ Layout planning

\section{Introduction}

This chapter describes the Use-it-Wisely (UIW) approach being implemented in the industrial production of automotive products in the heavy and medium sized truck segment. The high investment product-service referred to in this part of the project is

\footnotetext{
J. Berglund $(\bowtie) \cdot$ L. Gong $\cdot$ H. Sundström $\cdot$ B. Johansson

Product and Production Development, Chalmers University of Technology,

Gothenburg, Sweden

e-mail: jonatan.berglund@chalmers.se

L. Gong

e-mail: liang.gong@chalmers.se

H. Sundström

e-mail: suhanna@ student.chalmers.se

B. Johansson

e-mail: bjorn.johansson@ chalmers.se

(C) The Author(s) 2017

S.N. Grösser et al. (eds.), Dynamics of Long-Life Assets,

DOI 10.1007/978-3-319-45438-2_14
} 
thus the production system put in place to physically realise the trucks developed and sold by Volvo Group. The act of establishing a production system, the truck factory, is indeed related to a high investment and a long term commitment. The truck manufacturing industry is characterised by high product variability (Johansson et al. 2016). This means that customers are able to customise their purchases by selecting various features to a high degree. While this is a competitive advantage in the market place, it can be both costly and technically challenging to realise on the manufacturing side. In short, for a production line to reach optimal efficiency it needs to be perfectly balanced, meaning that the work carried out in each step takes an equal amount of time to perform. It is theoretically possible to design such a production line, given that each product is identical, from an assembly process perspective, to the previous/next one. In the case of products as component rich and complex as trucks this is never the case, and instead, manufacturing companies resort to managing the variation in their products. In the end, it comes to a trade-off between flexibility and cost.

A manufacturing system is a complex entity consisting of several subsystems such as building infrastructure, material handling, equipment, electrical wiring, maintenance and support, and so forth. These subsystems are different in nature. For example, the building infrastructure is physical and rather stationary; walls can be torn down or put up and the roof can be lifted but for the most part the building exists as it is. The material handling subsystem is necessary for the operation of the plant. It consists of, for example, physical assets like storage structures, forklifts that move products and components, software that handles the manufacturing execution information, and the personnel in the logistics department. All these subsystems share the same physical space where they need to co-exist and, ideally, function in harmony to achieve the overall goal of the manufacturing system.

As the product, the truck, develops and changes over time, to follow market trends, regulations, and technical innovations, so must the factory that produces it. This again emphasis the continuous need for upgrades and improvements on the existing manufacturing system over time. However, the upgrade and improvement process of a factory is a complex task, as indicated by the many subsystems and actors that exist in it. The actors, or functions if you will that are responsible for doing so are often not directly involved with the operational activities and day to day workings of the factory itself. As a result, there is a largely underutilised body of tacit knowledge and experience represented in the operational part of the organisation. If this knowledge and experience can be utilized in upgrade and improvement projects, the information input of these projects would be expanded. It is important to capture the viewpoint and perspective of all involved actors in order to make informed and holistically beneficial decisions. The work behind this chapter has put a lot of focus on reaching and harnessing this knowledge and experience in areas where it was previously overlooked. The hypothesis is that by involving relevant actors and stakeholders in the upgrade process there is a reduction of the risk of errors and a higher frequency of first time right in the process of upgrading the manufacturing system.

This chapter presents the development and evaluation of methods and tools that support the production engineering organisation to carry out the planning and design of upgrades of the production system. The approach combines 3D-imaging 
technology and the latest in virtual reality to make the design and planning process more inclusive and to draw upon the tacit and empirical knowledge of the operative actors in the production organisation.

This chapter is structured as follows: Sect. 2 provides an introduction to the automotive production system at hand. Then, Sect. 3 presents the application of the collaborative tool, previously described in Chapter "Operator-Oriented Product and Production Process Design for Manufacturing, Maintenance and Upgrading”, in the production system context. Finally, Sect. 4 gives a summary of the findings based on surveys and interviews with pilot users of the developed tools.

\section{The Industrial Case}

This section provides an overview of the production system at Volvo Trucks, which has been the specific subject of this work. The purpose is for the reader to get a feeling for the environment and context which has shaped the development of tools and which is the basis for evaluation of the implementation of the tool.

\subsection{Describing the Problem}

The Volvo Trucks manufacturing organization is represented on every continent, totalling over 20 factories worldwide taking part in producing the various models and brands of Volvo Groups Truck Operations (Volvo Group Financial Report 2014). As a manufacturer of automotive products Volvo is bound by regulations and strict rules for conformance to these regulations. This means that a much of the product is subject to testing with regards to function, safety, and quality. But how does such a large company ensure that their products are produced in the same way and with the same result in all of their various locations? Often times, work conditions and workplace safety regulations differ between countries, not to mention between continents. And the manufacturing equipment and machinery which is available for purchase in Kaluga, Russia, may not be available to the plants in the US or Brazilian markets. Transporting equipment across borders is costly and would result in dependency on a supplier that is situated half a planet away.

To combat this, and related issues, Volvo uses something called Master Processes. These are guidelines that govern any business process within the company, including manufacturing. It sets the basic requirements of the process, and gives guidelines to how it should be designed. Take for example the assembly of the firewall component. The firewall is a barrier situated in front of the driver in the cab, it separates the driver environment from the engine. If the assembly of the firewall is performed according to the same specification in the various plants there is a greater probability that the resulting trucks are equal. Another benefit with this 
Table 1 Targeted impacts and means of attacking them for the collaborative approach of managing upgrades

\begin{tabular}{l|l|l}
\hline Targeted impact area & Means of impact & Variable name \\
\hline $\begin{array}{l}\text { Production and delivery of } \\
\text { personalised final products }\end{array}$ & $\begin{array}{l}\text { Rapid reconfiguration of production } \\
\text { system based on point-cloud scanned } \\
\text { facility models }\end{array}$ & $\begin{array}{l}\text { Market agility } \\
\text { and flexibility }\end{array}$ \\
\hline $\begin{array}{l}\text { Cost and time in product/process } \\
\text { development }\end{array}$ & $\begin{array}{l}\text { Proactive system testing and } \\
\text { pre-validated performance }\end{array}$ & Ramp-up time \\
\hline $\begin{array}{l}\text { Time reduction for new processes and } \\
\text { plant designs }\end{array}$ & $\begin{array}{l}\text { Virtual assessment of } \\
\text { manufacturability based on hybrid } \\
\text { digital models (3D scan + CAD). } \\
\text { Proactive development and operator } \\
\text { training efforts }\end{array}$ & $\begin{array}{l}\text { Production set } \\
\text { up time }\end{array}$ \\
\hline $\begin{array}{l}\text { Environmental footprint and the } \\
\text { resources consumption during the } \\
\text { production and use phase }\end{array}$ & $\begin{array}{l}\text { Reduction of error rates, scrap and } \\
\text { waste generated by the production } \\
\text { system }\end{array}$ & $\begin{array}{l}\text { Environmental } \\
\text { footprint }\end{array}$ \\
\hline
\end{tabular}

strategy is that improvements to the processes that are found in one location of the globe are possible to implement in all other locations. This strategy can found in other sectors, for example in heavily standardised fast-food restaurant chains. These tend to be constructed in a very similar way regardless of their location, especially the production system, e.g. kitchen and ordering section. Thereby allowing companies to collect data from several locations and aggregate them to draw more robust conclusions in a limited amount of time. Furthermore, it makes it possible to implement operational improvements invented and validated in one location across the entire organization.

As can be inferred by the above section, there are many challenges facing a production company in this sector. At the outset of the UIW-project, a number of areas were targeted to bring improvement to the change and upgrade processes, see Table 1.

\subsection{Actors and Their Tasks in the Production Organisation}

The production system is a cyber physical system in the sense that it consists of technical equipment and machinery that is, to a large extent, operated by humans following a set of rules and methods. Therefore, to make any attempt to change and impact the operations of the production system it is important to understand its users, from here on out referred to as actors, and their relation to each other and the technical system. To understand who the actors in the production organization are and what work tasks they perform, a mapping effort was carried out. The mapping was supported by data from three sources within the company: 
- Available documentation: All work positions are described in documentation in the Human Relations (HR) department. The information is used for hiring new personnel and the content is the responsibility of the technical manager of the relevant area. These documents provide a technical and objective view of the different actors involved.

- Discussions with researchers: Through open dialogue with researchers that participate in the UIW-project a rich picture was created. The rich picture maps both internal and external actors on a more abstract level, to model their needs and motivations and how they relate to each other.

- Structured interviews with managers in the production organisation: There were three departments in the production organisation responsible for change work. Managers from each department were interviewed about the practical implementation of the change process. Some of the practices differ from the documentation, and in some instances the output from these interviews helped clarify and interpret the formal information.

The following actors along with their work tasks were identified during the process:

- Line Builders: This actor represents the external suppliers of machines, tools and equipment for installation and integration into the Volvo production system.

\section{Responsibilities:}

- Delivery and installation of equipment.

- Service of equipment according to service level agreements.

- Support in training of maintenance personnel.

- Support in improvement, re-furbishing and new investment of equipment.

- Managers: This actor represents the management of Volvo production facilities.

Responsibilities:

- Lead and control the operations.

- Manage personnel, follow legal instructions on work environment.

- Development of processes and personnel.

- Take decisions on improvements and investments.

- Implement changes in the production system when needed.

- Follow-up on operative KPIs.

- Drive strategy work.

- Maintenance planner: This actor represents the role of maintenance planning in the factory.

\section{Responsibilities:}

- Planning and preparation of work-orders and planned maintenance by ordering the needed material and services.

- Provide work-instructions when needed. 
- Daily/weekly planning, weekly reports.

- Analysis and follow-up of work-orders with the maintenance personnel.

- Ordering of spare parts, materials and services.

- Work cross-functional and participate in needed forums.

- Educate personnel in maintenance planning system.

- Track and follow-up on maintenance KPI's.

- Contacts with suppliers of equipment and machines (service, purchasing, ordering).

- Equipment and machine management and handling of unit exchanges.

- Manufacturing Engineers: This actor represents technicians of Volvo in charge of the design and implement of any update or change into the production system.

\section{Responsibilities:}

- Follow-up, analyse and improve the process within the delegated area of work regarding quality, OEE and productivity.

- Propose and implement improvements.

- Perform studies on methods and update description on methods within the delegated area of work.

- Preparation and planning of manning, operations, work instructions.

- Participate in work environment meetings.

\section{- Simulation and layout technicians/engineers:}

\section{Responsibilities:}

- Performs simulation assignments on product and process, off-line simulations.

- Strategies on off-line robots for production, introduction of new solutions.

- Understanding of visualization, simulation, off-line programming in production.

- Investigations on process and product regarding flows, stations and fixtures.

- Ensure that changes are implemented according to strategies and VPS directives.

- Develop and present suggestions for improvements.

- Coordinate changes in process layouts (2D and 3D).

- Participation in Volvo Virtual Manufacturing network.

- Operators: This actor represents shop floor operators of Volvo that performs the daily work in assembling the product.

\section{Responsibilities:}

- Follow work instructions.

- Perform assembly and material handling.

- Quality assurance of product assembly.

- Report issues on product or process/methods to manufacturing engineers. 
- Material Handlers/logistics engineers: This actor represents technicians of Volvo working with internal material handling and logistics.

Responsibilities:

- Support internal Material Handling organisation with Logistics.

- Engineering work (manning/balancing, material façade, routing etc.) in selected areas.

- Support Global Sourcing logistics representatives in the sourcing process.

- Prepare selected new parts and suppliers for being taken care of, and implemented in a quality assured way.

- Parameter settings needed in local material systems for selected parts and suppliers.

- Continuously monitoring of, and act on, compliance to or any need of changes in-present logistics set up due to changes in e.g. volumes.

- Follow up globally agreed, or other relevant, (K)PIs.

- Participate in the continuous improvement work in the daily work.

- Participate in local/regional a/o global networks to contribute to the process development.

- Introduction Engineers: This actor represents Engineers of Volvo working with introduction of product changes into the production systems.

Responsibilities:

- Keeping the global master processes updated and compatible with the new products.

- Work on a local, regional and global level to adjust and align manufacturing processes.

- Coordinate the testing and verification of new products into the production system.

- Assess and abridge consequences and product- and production requirements between construction and product development departments.

- Coordinate the introduction of new product change orders.

- Assess and abridge product- and production requirements between manufacturing engineering/product development and local site technicians.

- Coordinate product and process issues with local site technicians.

A holistic system understanding is of great importance when working with complex systems (Checkland 2000). To place the identified actors and their work tasks in context, a rich picture (or context map) was created during a workshop. The picture links the actors and their motivations and needs with each other and the core entities of the company, Fig. 1.

The rich picture takes on the perspective of the manufacturing organisation and centres on a factory. At the core are things that the manufacturing organization can control to some extent. Such as the production line, the work instructions and the maintenance. Further out from the centre are entities that exist in the environment 


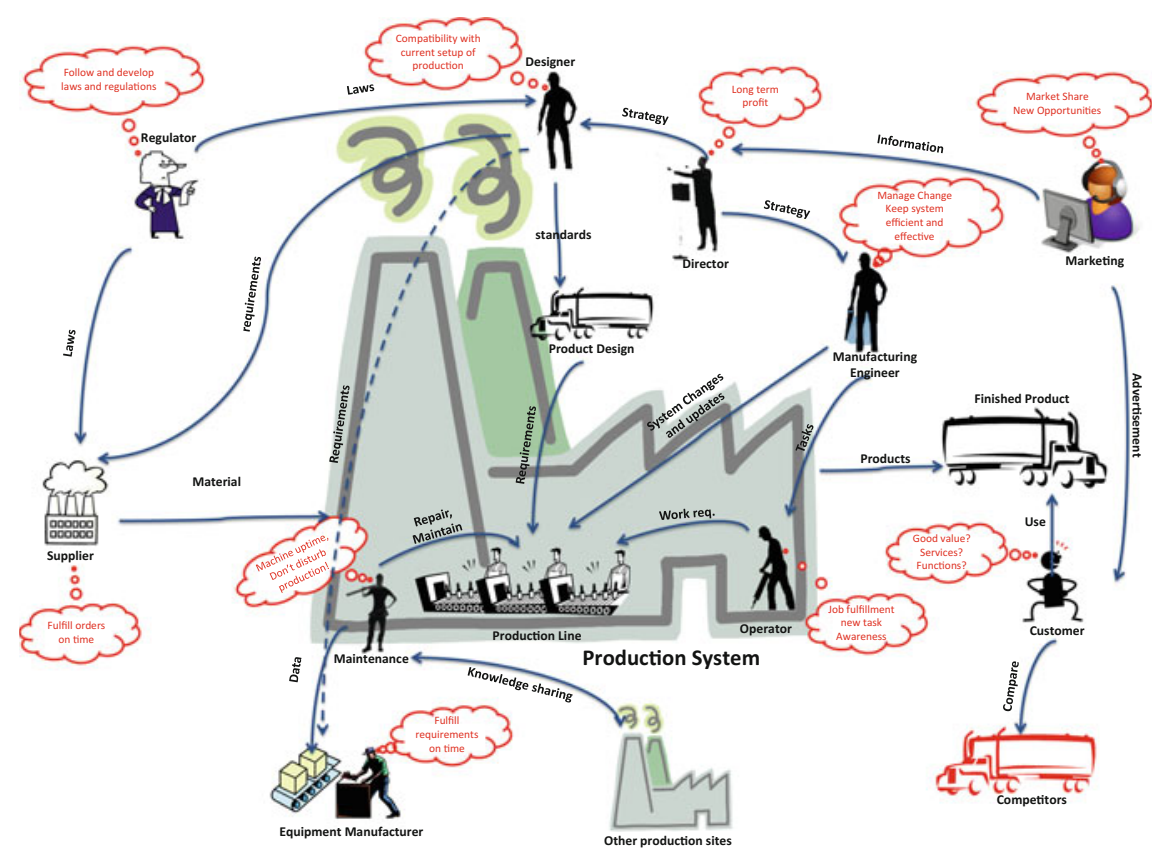

Fig. 1 Rich picture illustration of the different actors, their motivations and relationships to the manufacturing system

around the factory. These can be internal to the overall organisation, such as product designers, marketing department, and other production sites. They can also be external to the overall organisation, such as the customers, legislators, and suppliers. Together this network of actors creates a very complex canvas on which the manufacturing of trucks must exist and perform over time.

\subsection{Adaptation of Production Systems: Changes and Upgrades}

As stated in the introduction to this chapter, the truck manufacturing industry is a high variant product sector, and as such it is prone to changes (Johansson et al. 2016). Changes in the production systems of Volvo are driven by needs coming from either the product or the production process itself. Product driven change occurs when the product changes, or when new products are introduced. Process driven changes are motivated by cost savings, technology upgrades, or quality issues. Also business related motives such as moving parts of production in-between production sites can be said to belong in the process driven change category. Through interviews with company employees at management level and 


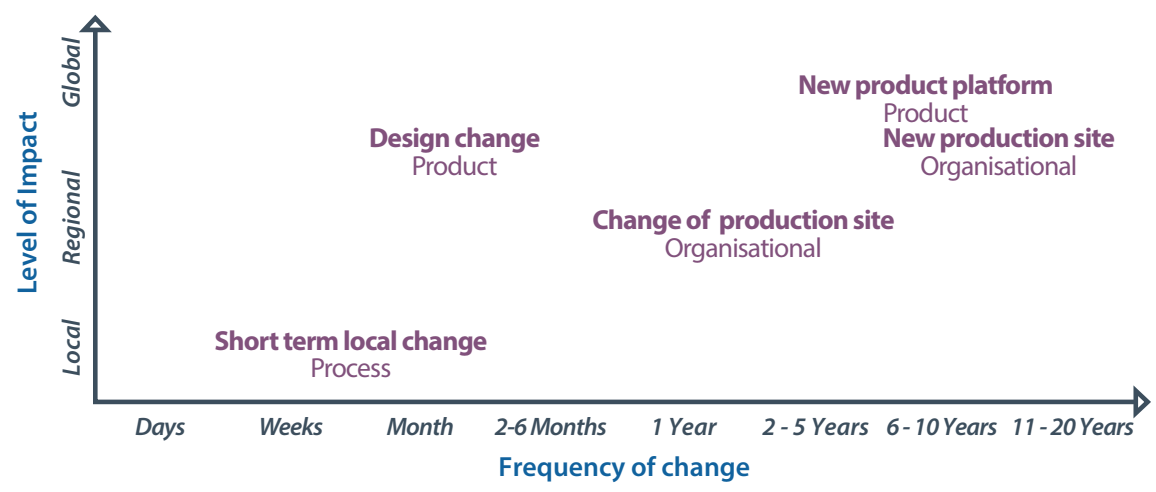

Fig. 2 On production system change at Volvo Trucks; their frequency and level of impact on the organisation

documentation in production project process guidelines, a number of change types were identified. These types along with their frequency and level of impact are visualised in Fig. 2.

As mentioned earlier, there are guidelines and steering documents that govern the change and upgrade process. Depending on the impact and size of the change process, different sets of guidelines and steering documents are applicable. To gather these guidelines and support engineers that work with changes, Volvo has developed a project steering model. It covers all project stages chronologically starting from the investigation stage, which covers the needs and drivers for change, through to the ramping up of production in the new system and a follow-up on the results. While this project steering model is used by the engineer managing the change process, many of the actors described earlier are involved through their stated work descriptions.

Anytime a change or upgrade is to be implemented in the factory, it has to be planned for and modelled in advance as to not disturb the ongoing operations more than necessary. This is due to the fact that a production system is a high cost investment that relies on continuous use, e.g. the manufacturing of products, to bear its investment cost. For these models to be valuable and valid as decision support they need to accurately reflect the current conditions of the system (Berglund et al. 2016). Figure 3 shows an example of a model from the robotic laboratory at Chalmers, incorporating the 3D imaging technologies described in Chapter "Operator-Oriented Product and Production Process Design for Manufacturing, Maintenance and Upgrading.

There are oftentimes CAD models of the production system available that were created during the installation of the system, or at the latest change or upgrade to it. However due to the natural entropy of such complex systems, such models are seldom up to date with the current conditions. Using out of date models can lead to unforeseen issues such as new equipment not fitting into the allotted space, or that developed solutions are not feasible in reality. By using a modelling tool which can 


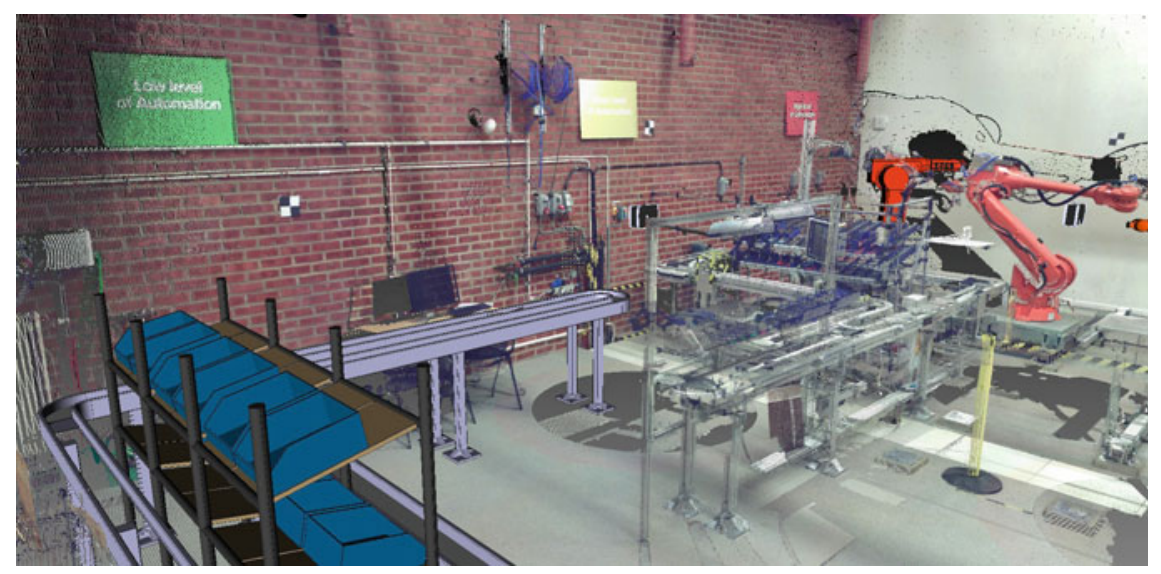

Fig. 3 A hybrid point-cloud and CAD planning environment to position a conveyor in the existing factory layout

include spatially captured properties of the existing environment, e.g. 3D-imaging data, companies can reduce the risk of bad decision due to outdated or incorrect information, while saving time and money in the planning phase of new development projects (Lindskog 2014).

As previously mentioned, a holistic approach and view of the system is necessary to avoid sub-optimization and to leverage resources in an effective way. One way of achieving this is cross functional actor involvement, and letting the end users of the system have a say in the planning process. In the case discussed here, end users are represented by e.g. assembly operators, material handlers, or maintenance engineers. One benefit of involving end users is the possibility to tap the empirical knowledge and practical knowhow that system design engineers might be lacking. The research carried out in this project looks to harness that empirical knowledge and make use of it in the planning process to improve the end result while decreasing the risk of making costly and time consuming mistakes.

\subsection{The Volvo Trucks Production System as a Product-Service System}

In addition to the actor and task mapping conducted in the previous sections, a third model was generated to better understand the setting and current state. It explicitly divides the production organisation of Volvo into Actor, Product, and Service categories. The Product Service System (PSS) is a concept developed for supporting sustainable consumption where the producer retains responsibility of the product throughout the use phase by selling its function as a service rather than the physical product itself (Mont 2002). This model fits well with how a production system is thought within an industrial company. It is an investment bought and sold 


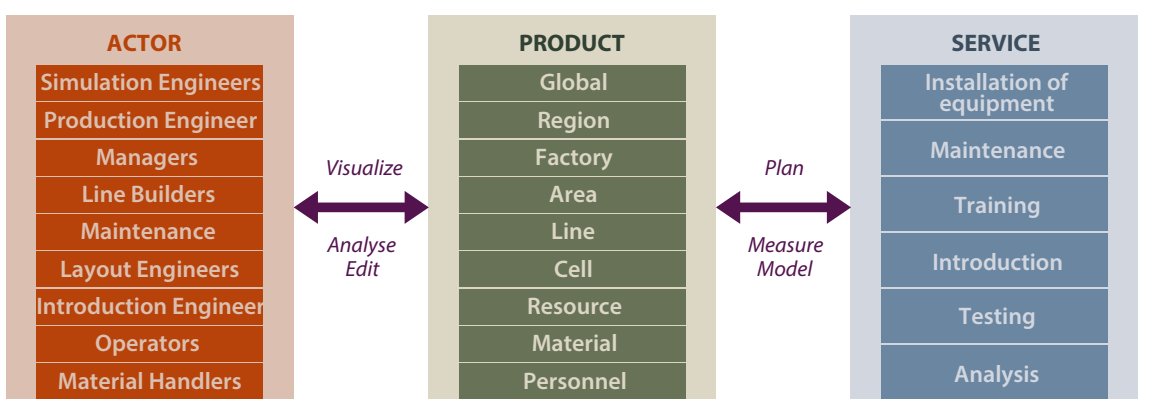

Fig. 4 Actor PSS model of the production system at Volvo

within the company and both the seller and buyer are equally adamant of keeping the system functional, providing the service of producing vehicles. Thus, the product in the view adopted by the project, are the components of the production system. The APS model was used to infer how a 3D visualisation tool could be linked to the system. The mapping of the Actor PSS that was defined for a general production system for trucks can be seen in Fig. 4.

The actor part includes all the identified actors from Sect. 2.2. The product part concerns the production organisation broken down hierarchically from the global organisational level down to the actual resources on the factory shop-floor. The service part holds a list of the main activities which are carried out by those resources.

\section{Development and Evaluation of Collaborative Tool}

This chapter describes the development of the tool for the industrial case. It exemplifies use cases within the manufacturing development process at an automotive company where a need for this technology has been identified. A demonstrator that was developed is described and finally the results from testing the demonstrator with end users within an industrial company.

\subsection{Development of the Technical Solutions}

As mentioned in the previous section, the solution should support planning of upgrades and changes to the existing system by providing an accurate current state model and a realistic and intuitive visualization environment to elicit domain expert feedback. The improved current state representation reduces risk of taking decisions based on faulty data. The realistic visualization lowers the threshold to understanding the model so as to make the involvement of stakeholders from different areas of expertise easier. The solution was developed in an iterative fashion, starting 
in a laboratory environment at Chalmers University of Technology. That stage of development was then implemented using Volvo factory equipment and production system environment. Based on the response the solution was refined and improved further before finally being applied to several factory units at Volvo.

The demonstrator case used for the development of this tool was looking at the early design phase and the involvement of cross functional actors. Figure 5 below depicts the focus of this project, in the context of a simplified version of the production project methodology used at Volvo Trucks.

The demonstrator case chosen was looking at the early design phase and the involvement of cross functional actors.

The demonstrator consists of a virtual model of a Volvo factory in United States. The virtual model is a hybrid using both measurements captured using 3D imaging technology and CAD data. The demonstrator is accessed using a VR kit from HTC. The architecture of the demonstrator is set up according to Fig. 6.

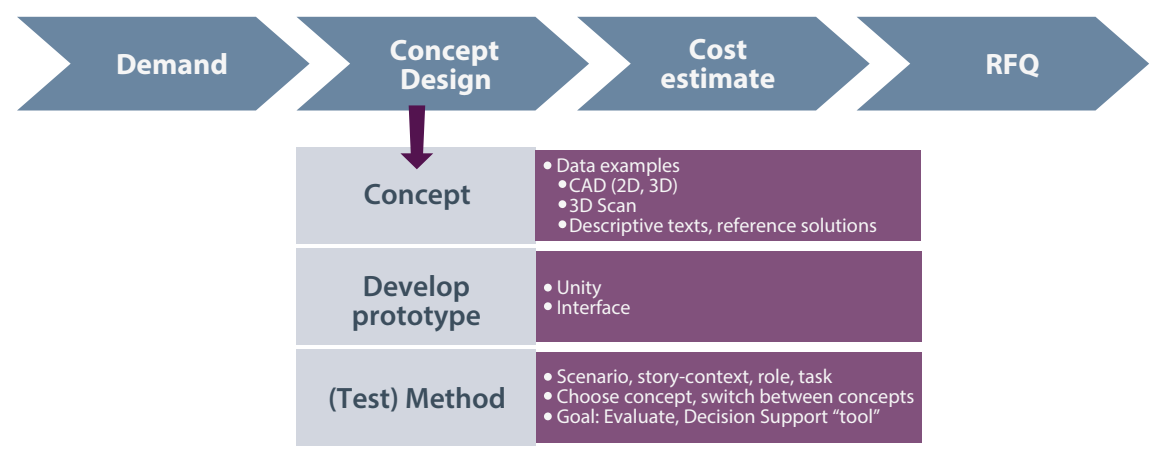

Fig. 5 Process targeted by the demonstrator, put in context of a simplified version of the production project methodology in use at Volvo

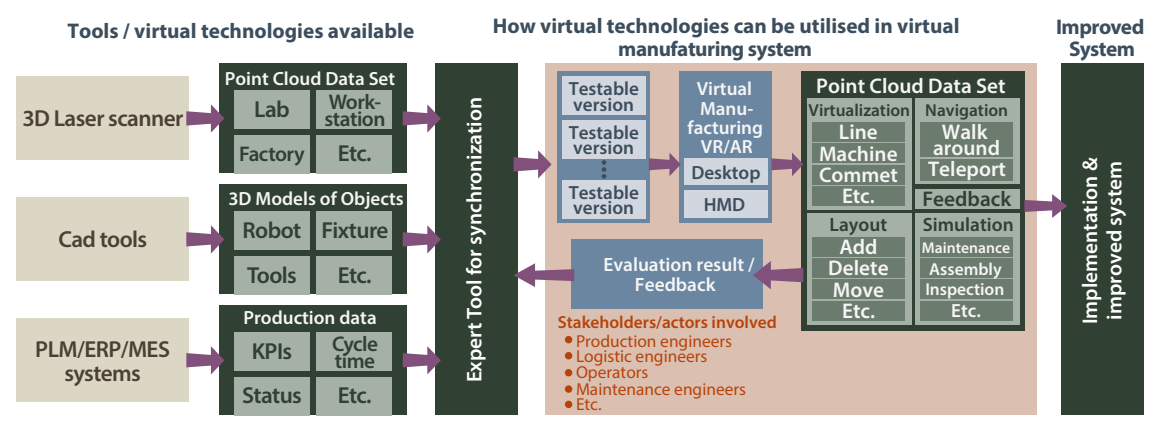

Fig. 6 Architecture of the collaborative VR tool 
Table 2 3D imaging data summary

\begin{tabular}{l|l|l}
\hline & Firewall cell & All data collected \\
\hline No. scans & 5 & 82 \\
\hline Area coverage & $390 \mathrm{~m}^{2}$ & $6600 \mathrm{~m}^{2}$ \\
\hline Size of raw data $\left(. \mathrm{fls} \mathrm{a}^{\mathrm{a}}\right)$ & $843 \mathrm{MB}$ & $13,840 \mathrm{MB}$ \\
\hline $\begin{array}{l}\text { Size of processed data } \\
\left(. \text { off }^{\mathrm{b}}\right)\end{array}$ & $714 \mathrm{MB}$ & $\mathrm{n} / \mathrm{a}$ \\
\hline & Firewall cell & All data collected \\
\hline
\end{tabular}

${ }^{a}$ Native scan data format of FARO laser scanners (www.faro.com) ${ }^{\mathrm{b}}$ Object file format a geometric data format that was used to import 3D imaging data into unity $3 \mathrm{D}$

The 3D imaging data was captured by Volvo employees and assembled by researchers from Chalmers University of Technology. The data was then combined with CAD data to form the virtual model in Unity 3D environment. The user goes through a short training scenario and is then presented with the factory model. During the demonstration the user is able to modify the layout and store the changes. He or she can load stored layouts from other users and review them by leaving feedback on selected features in the layout.

The data collection was conducted by Volvo employees on site at a Volvo run plant in the United States. The data collection was conducted during two days and resulted in a total of 82 individual scans, covering a large portion of the main assembly line. The section of the factory that was used for the demonstrator, the firewall subassembly consists of only five scans, but data from surrounding areas were also included to give context to the cell which is a part of the whole. Table 2 gives more details on the data collected in the US factory.

\subsection{Implementing the Demonstrator Solution}

The focus of the demonstrator was the design stage for upgrades of existing production system infrastructure. In this process there is an overarching goal of adhering to global manufacturing guide lines, i.e. the Master Process, as well as aligning the different production sites to a more homogeneous manufacturing solution. This can potentially increase consistency in quality and improve the possibility to spread improvements and kaizen work throughout the organization. (e.g. an improvement found in One factory can immediately be introduced also in other factories). This ties back to reaching actors in different location with the concepts. An actor working with the fire wall process in factory A can look at and assess the corresponding fire wall process in factory B, and thereby learn from other company sites. 
(a)

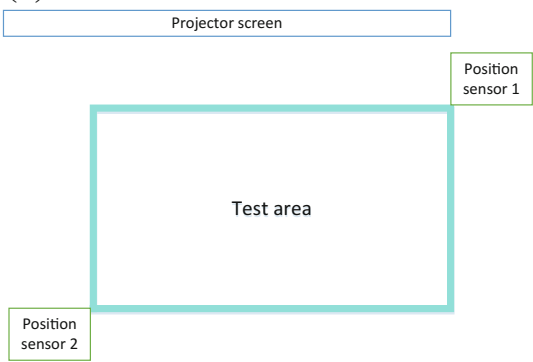

(b)

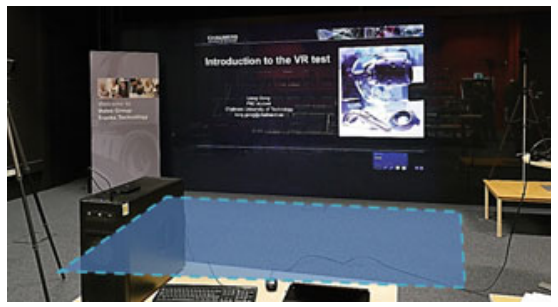

PC Station

Questionnaire desk

Fig. 7 Demonstrator setup: (a, left) schematic illustration, (b, right) photograph, the outlined rectangle indicates the test area

The demonstrator was set up in Volvo facilities, in an auditorium with a stage area and a back projected screen. The setup consisted of:

- A PC station with demonstrator software

- Positioning sensors on tripods to track the VR space ${ }^{1}$

- Head mounted display (HMD) ${ }^{2}$

- Two hand held controllers for interacting with the VR environment ${ }^{3}$

- Presentation screen used to give instructions before the test and to duplicate the VR user's view for onlookers and researchers during the test

A schematic overview and a photo of the test facility can be seen in.

To the left and rightmost sides of Fig. 7b are tripods holding sensors that continuously tracks the location of the HMD and the two controllers. Near the front of the picture is the PC that runs the software and in the background the back-projected screen is visible. Data extracts from the demonstrator depicting the current conditions of the Fire wall production cell as captured using a 3D laser scanner is shown in Fig. 8.

In total, participating in the demonstrator evaluation were nine persons from different actor groups within Volvo and one senior researcher in the field of virtual production from the research team at Chalmers. The participants where all involved in the engineering side of the organization, working with $R \& D$ related to manufacturing. The average age of the group was 38.8 years.

\footnotetext{
${ }^{1}$ Part of the HTC Vive kit.

${ }^{2}$ Part of the HTC Vive kit.

${ }^{3}$ Part of the HTC Vive kit.
} 
Fig. 8 3D laser scan data of the production cell used for the demonstrator

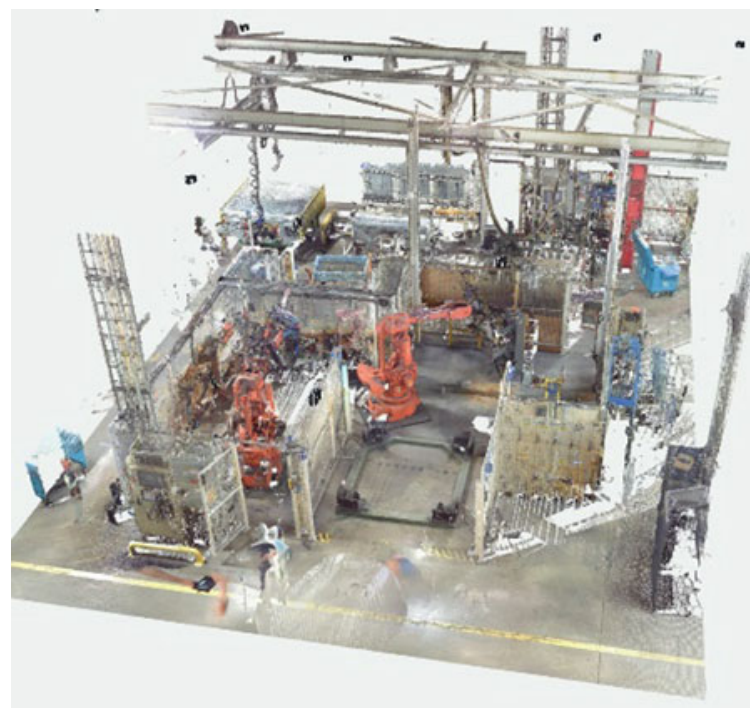

\subsection{Conducting the Evaluation}

The demonstrator evaluation was initiated by the researchers introducing the UIW-project, along with its aim and scope. Then a presentation detailing the test procedure was given collectively to the test subjects (the subjects were brought in groups of 1-4 persons). The procedure of the demonstrator was as follows:

In group:

- Overview of the VR application structure-Description of the system and motivation behind it

- Getting started-Theoretical introduction to the VR system and how to interact with the system

Individually:

- Testing the equipment-The participant familiarizes with the interface in a test environment

- System demonstration-The participant conducts a series of tasks in the demonstrator system

- Questionnaire feedback-The participants document their experience by answering a questionnaire

During the individual portion of the evaluation, each of the participants in turn wore the VR gear and conducted a series of tasks in the modelled environment. The tasks consisted of an initial training scenario where the participant is given basic instructions to familiarize with the VR equipment. These tasks include navigating through the environment, interacting with objects by grabbing and moving them, 
leaving feedback by pointing at objects, and using the menu system to store and load configurations of the environment. This training and introduction was carried out in a model of the Chalmers production system lab, screenshots from the training module of the demonstrator can be seen in Fig. 9.

Once the participant was familiar with the navigation and controls they were asked to proceed to the next step of the demonstration. In the second step the participant is shown a scaled down version of the 3D imaging data of the US factory, positioned on a table. The participant can walk over the model and inspect the layout of the plant. The participant is then asked to locate the highlight area, which is the fire wall cell. By using the hand controller to touch and click the volume of the fire wall cell area the participant is moved into a full sized model of the cell. In this environment the participant was given some time to explore freely, using the navigation controls, before being given a set of tasks. The tasks were a
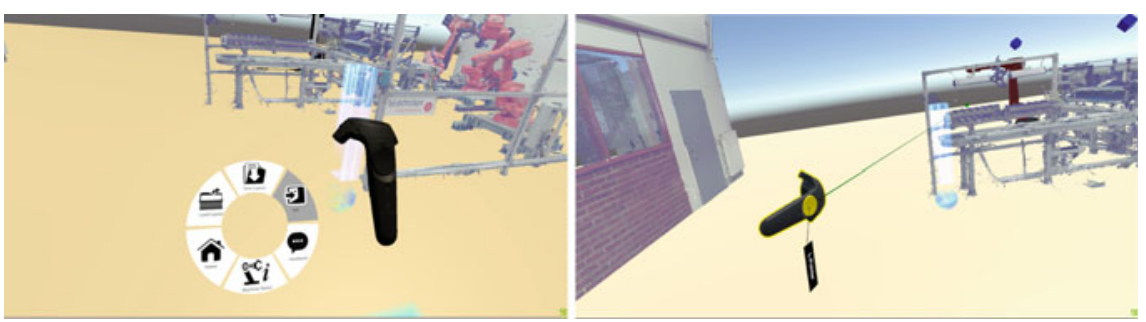

Fig. 9 Screenshots from the training environment depicting the menu and pointing activities

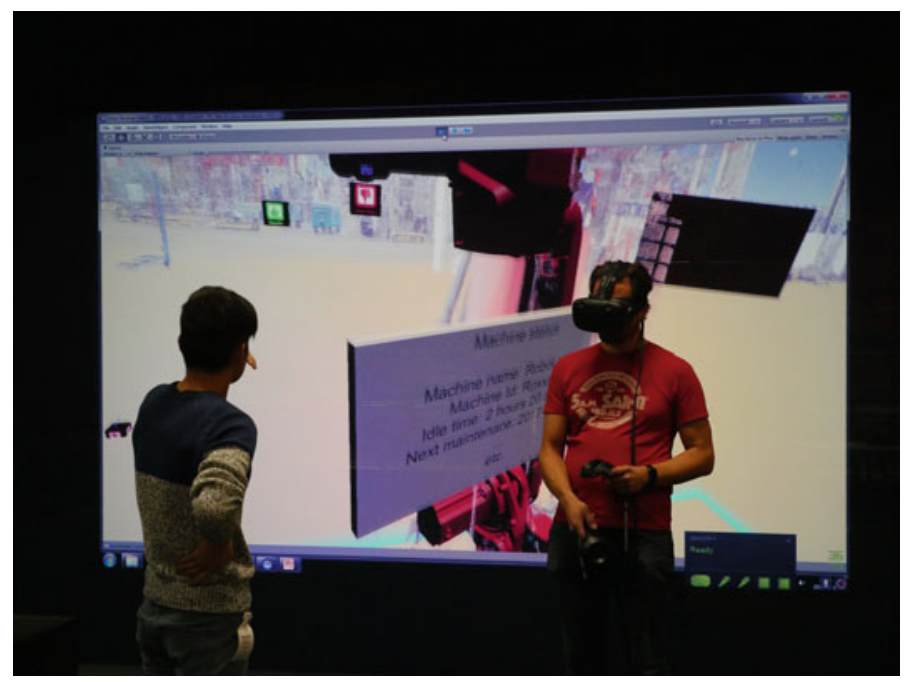

Fig. 10 Participant (on the right) being guided by a facilitator (on the left) during the demonstrator evaluation 
repetition of the training tasks, but where given in a non-explicit manner, such as move objects to the positions you see fit or leave comments indicating if you like or dislike some feature of the model. The fire wall cell model also included virtual information plates with equipment data. A picture showing one of the participants while interacting in the real sized virtual factory environment is seen in Fig. 10.

After completing the tasks in the demonstrator scenario, each of the participants were given a questionnaire to fill out. The results from the questionnaire are presented in subsequent sections.

\subsection{Result from the Evaluation}

The questionnaire had two parts, one qualitative which leaves room for the respondents to express in words their experience, and to motivate their choices in the quantitative part which ask the respondents to rank different aspects of the demonstration and the value of the proposed system to different stakeholders. Figures 11 and 12 below summarises the quantitative responses that were given by the test persons.

From the responses it is clear that a majority of the test persons saw benefits from the system, for the various stakeholders. Most benefit was recognized to the user, in other words the engineers and the factory personnel who would use it to develop better upgrades. While no one disagreed strongly about the benefits of the system, one users was not sure about there being clear benefits to Volvo from using it. However, that same user agreed to the overall benefits to different stakeholders in the second table, Fig. 12.

Table 3 shows the qualitative questionnaire responses from the demonstrator subjects. In the comment sections some reoccurring themes were positive benefits such as easy to use, visually representative of the real factory, accurate and "near" life like experience. Some obstacles that were detected was dizziness when using the HMD (one user), disorientation (one user), and that the tool as such/interfaces took some time to get used to (two users).

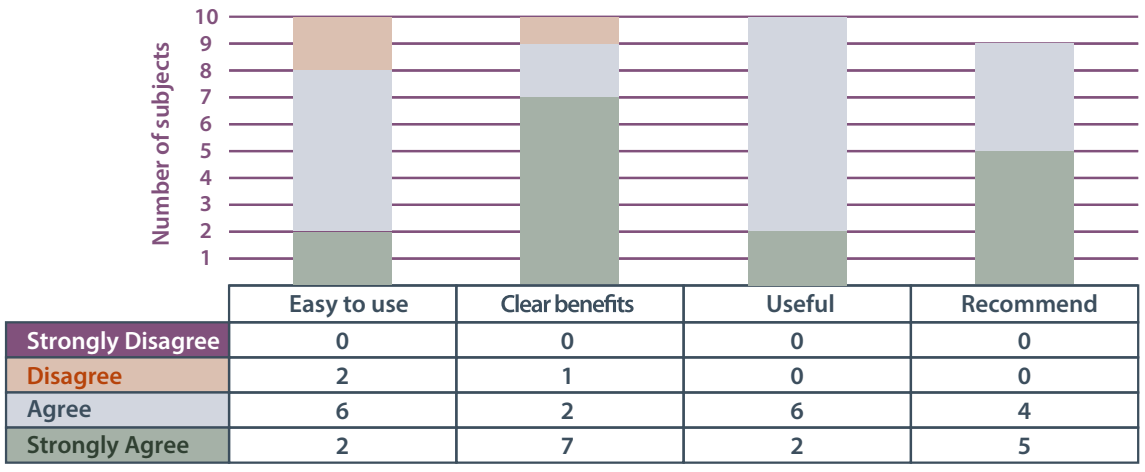

Fig. 11 User feedback on the collaborative VR tool design concept evaluation 


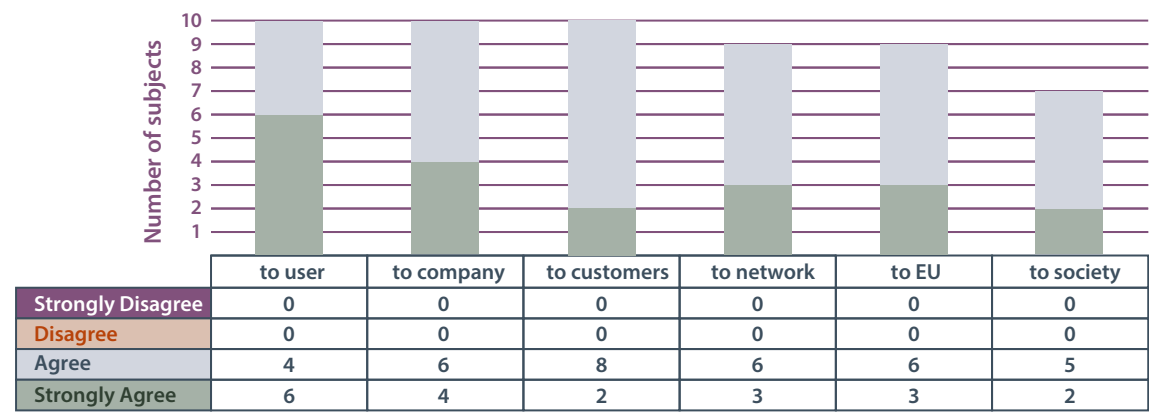

Fig. 12 User feedback on the benefits/value of the collaborative VR tool to different stakeholders

Table 3 Benefits/value at different levels of impact based on questionnaire and interviews

\begin{tabular}{l|l}
\hline End user & Benefits, value \\
\hline Company & $\begin{array}{l}\text { The virtual model is easy to understand. Easier than previously } \\
\text { experienced models. It is easier to navigate the model in this way. More } \\
\text { functions could be implemented dealing with trial and error }\end{array}$ \\
\hline Customer & $\begin{array}{l}\text { The system supports giving users the same view of the production } \\
\text { system. It gives better understanding. Of course the system could provide } \\
\text { value. One user was not sure about the value on a company level, and } \\
\text { another stressed the importance of that it should be easy to prepare the } \\
\text { input, preferably through integration with the existing PLM platform }\end{array}$ \\
\hline Value network & $\begin{array}{l}\text { The system can provide value to the customers on a long term basis. And } \\
\text { that the work and communication with them can work quicker }\end{array}$ \\
\hline EU & $\begin{array}{l}\text { Respondents stated that this system can make interactions easier. And } \\
\text { also that it would be nice with many users sharing the same environment } \\
\text { simultaneously }\end{array}$ \\
\hline Community/society & $\begin{array}{l}\text { On an EU level the respondents felt that the system can lead to better } \\
\text { understanding, more interaction, and therefore better decisions. One } \\
\text { respondent said: "Will push EU as an enabler of new technology" } \\
\text { Generally a lot of focus was placed on faster and easier decision making } \\
\text { and communication quality. Ultimately leading to better products } \\
\text { delivered }\end{array}$ \\
$\begin{array}{l}\text { On the societal level some users saw direct benefits through shifting some } \\
\text { processes to the digital world and thus requiring less travel needed and } \\
\text { reduction of material used for prototyping. At the same time some of the } \\
\text { respondents were not sure about the benefits at this moment }\end{array}$ \\
\hline
\end{tabular}

When asked about other uses and advantages of the system, respondents expressed that they either liked or wanted: Point clouds are good for quickly viewing actual station layout, system can be used to showcase new products/tools with its uses, and manufacturing simulation in VR.

The respondents were also asked in what areas within the manufacturing system that they saw uses for the collaborative VR tool. "In which areas of manufacturing do you think this system can be beneficial for the improvement of current work practice?". The categories that were presented to them are based on the work of Nee 


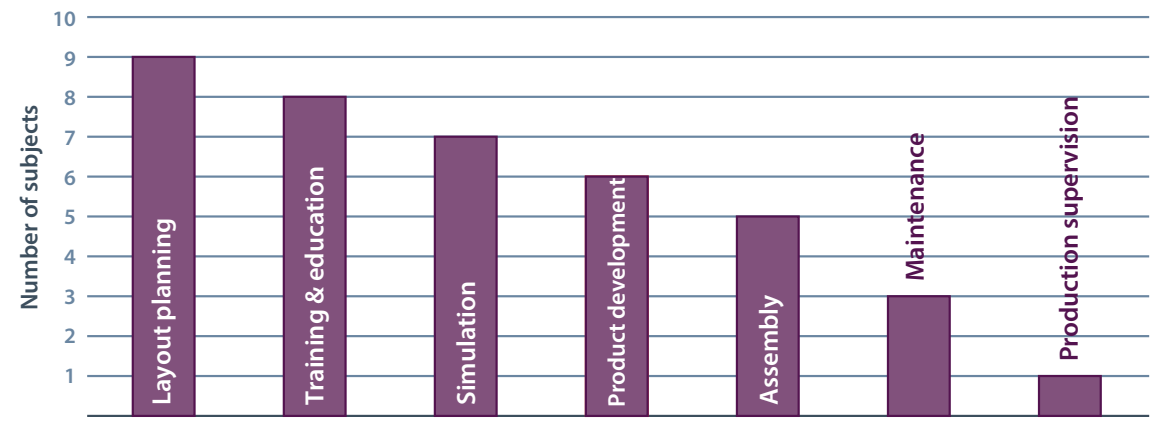

Fig. 13 Areas of application as selected by the respondents

et al. (2012). The most promising application areas was seen to be layout planning, training and education, and simulation. Figure 13 lists the aggregated results from this part of the questionnaire.

The things that users liked about the experience and system for virtually accessing the factory ranged from smart/easy interaction to novelty and state of the art. In general, the spatial understanding, realism, and the holistic visualisation of the production system was repeatedly stated as valuable. When asked about drawbacks the test subjects lifted that the point density in the Point cloud data was too low, this is a performance issue with the system where points have to be reduced to maintain an acceptable frame rate. For five of the ten respondents this was their first experience using VR systems. Towards the end of the questionnaire the respondents were asked:

"What challenges do you anticipate if your company is going to implement this VR systems?"

The answers given can be categorised into three different challenges: data compatibility, organisational attitudes, and cost. The first category is probably most central to the possible implementation at Volvo or any company. Data of the various aspects of the production system resides in many internal systems and in different formats. Accessing all of it seamlessly is a challenge, one that is addressed also in other research projects carried out within the Volvo Corporation. In addition, there would need to be an infrastructure in place to handle the 3D imaging data and making sure it is recent enough for it to be used. The second challenge relates to acceptance within the organisation. This requires education and training of users as well as incorporation into existing work methods. Finally, some of the respondents raised the issue of cost, where should the "burden" be placed on a system that does not exactly fall under any of the traditional department structures?

\section{Discussion}

As with any new tool or technology there exists both benefits and limitations and these will be discussed in the following chapters. 


\subsection{Identified Benefits}

3D-imaging provides visually realistic and geometrically accurate snapshots of the physical properties of the real world. The snapshots are stored in a format often called point clouds and can be used for modelling and analysis in virtual planning software. The point cloud data can be overlaid with other models and/or information regarding the various subsystems, separately or in parallel to find, discuss, and analyse issues and changes. Through the natural ease of understanding these models provide, they allow the various actors and experts that are using the system to express their different needs and requirements (Lindskog 2014). In this manner they can provide a valuable discussion ground and act as decision support for a manager, allowing him or her to make informed decisions with an expanded understanding of the consequences. Furthermore, it gives him or her a tool with which to visualize and communicate the decisions in a way that is approachable by all different actors regardless of technical background. By being able to include a broader range of actors and end users there is potential to gather a broader range of inputs and design comments to feed into the decision process.

Simplifying and speeding up the workflow to produce models enables iterative and frequent use of the models throughout the development process. It also means that a higher number of concepts and ideas can be tested and explored. The collaborative virtual reality models allow actors to experience the models in a 1:1 scale. Participants in the evaluation described that this gave them a better sense of the proposed solutions. Furthermore, the ability to share these realistic models with users in other departments or countries within the organisation was stated as a benefit.

Volvo has been working actively with virtual reality in a research capacity for several decades. However, it is only with the recent development and the introduction of VR on the consumer market that the usability and cost has created the conditions for making use of it in large scale, across the organisation. Previously, this technology work was limited to large test facilities and costly fixed installations. The ability to set up and implement solutions at a low cost means that investments in development of technical solutions and work methods can be shared and benefited from on a greater scale than before.

\subsection{Identified Limitations}

3D imaging is still an expert tool. And to introduce another expertize to the existing roles in the manufacturing organisation can prove costly. Furthermore, 3D imaging data capture is still a manual operation which requires users to access the production system at rest. This is costly, either through shutting production down or through accessing the system at night/weekend or vacation time. These requirements can limit the ability to collect new data on the fly or just-in-time as it is needed. At the same time, collecting data at opportune times, might mean that it is incorrect or outdated when it is needed in the decision making process. 
Another important aspect is that the $3 \mathrm{D}$ imaging models do not replace CAD representation in every aspect. 3D imaging data is a surface representations of the geometries present in the real world. As such they are missing design aspects and construction information that is key for some simulation and analysis activities. So while 3D imaging data is good for some activities there might still be need for high fidelity and detailed CAD representations for other tasks.

\section{References}

Berglund, J., Lindskog, E., Vallhagen, J., Wang, Z., Berlin, C., \& Johansson, B. (2016). Production system geometry assurance using 3D imaging. Procedia CIRP, 44, 132-137.

Checkland, P. (2000). Soft systems methodology: A thirty year retrospective. Systems Research and Behavioral Science.

Johansson, P. E. C., Mattsson, S., Moestam, L., \& Fast-Berglund, Å. (2016). Multi-variant truck production-Product variety and its impact on production quality in manual assembly. Procedia CIRP, 54, 245-250. doi:10.1016/j.procir.2016.05.062.

Lindskog, E. (2014). Towards realistic visualisation of production systems.

Mont, O. K. (2002). Clarifying the concept of product-service system. Journal of Cleaner Production, 10(3), 237-245.

Nee, A. Y. C., Ong, S. K., Chryssolouris, G., \& Mourtzis, D. (2012). Augmented reality applications in design and manufacturing. CIRP Annals-manufacturing technology, 61(2), 657-679.

Volvo Group. Volvo Group Financial Report. (2014). Retrieved on November 16, 2016 from http://www3.volvo.com/investors/finrep/ar14/sv/ar_2014_sve.pdf

Open Access This chapter is licensed under the terms of the Creative Commons Attribution-NonCommercial 4.0 International License (http://creativecommons.org/licenses/by-nc/ 4.0/), which permits any noncommercial use, sharing, adaptation, distribution and reproduction in any medium or format, as long as you give appropriate credit to the original author(s) and the source, provide a link to the Creative Commons license and indicate if changes were made.

The images or other third party material in this chapter are included in the chapter's Creative Commons license, unless indicated otherwise in a credit line to the material. If material is not included in the chapter's Creative Commons license and your intended use is not permitted by statutory regulation or exceeds the permitted use, you will need to obtain permission directly from the copyright holder. 